\title{
On the Way to Novelty - Society of Ambient Intelligence
}

\author{
Serhii Hushko ${ }^{1 *}$, Victoria Solovieva ${ }^{1}$, Andrii Shaikan ${ }^{1}$, Inesa Khvostina $^{2}$, and Serhii Semerikov ${ }^{3}$ \\ ${ }^{1}$ State University of Economics and Technology, 50005, Kryvyi Rih, Ukraine \\ ${ }^{2}$ IFNTUNG, 76000 Ivano-Frankivsk, Ukraine \\ ${ }^{3}$ Kryvyi Rih State Pedagogical University, Kryvyi Rih, 50086, Ukraine
}

\begin{abstract}
The ability to bring benefit to the society with the help of the artificial intelligence technologies within the short time drives the developers in many spheres. Modern developments are used to confirm the economic theories, in law-making, technical developments in the field of verification, data updating, security and control.
\end{abstract}

\section{Ambient Intelligence: Concepts and Understanding}

Ambient Intelligence combines several important areas of computing which are connected through new technology available. It allows developments which change the way system help us or can potentially help us in our daily life.

While the advent of the internet was certainly a ground-breaking milestone, digital technologies have not stopped evolving. The time when we had to turn on the computer and login to browse the worldwide web is coming to an end. Now, an important strand of information processing technologies is centered on the so-called «ubiquitous computing».[1] This concept derives from the philosophical or psychological observation that the best technologies are those that fade into the background when used. [2] Together, they connect people and deliver practical information through the cheaper, more efficient and more tailored services, while weaving themselves into the fabric of everyday life.[3] This is the essence of Ambient Intelligence (AmI), a concept built around the idea that, in a not so distant future, autonomic smart environments, based on profiling technologies, embedded sensors and sophisticated autonomous software, will take an unprecedented number of decisions for us and about us, to cater to our inferred preferences. [4]

The topic of the artificial intelligence is quite urgent and needs the scientific and practical evaluation of the prospects for its application. The speed of the artificial intelligence development will be determined by the external and internal factors. The external factors mean the speed of the data exchange within the "brains" of the artificial intelligence, within its network, as well as the speed of calculations, associated with it, and the availability of the information scopes, on the basis of which it will form its assumptions. The internal factors include the availability of energy to maintain its vital activity and the presence of channels for the receipt of the new information, so that the artificial mind, figuratively speaking, would enrich itself.

\section{ISC-SAI 2021 - current trends}

The realization of IV International Scientific Congress "SOCIETY OF AMBIENT INTELLIGENCE - 2021" allows us understand what we mean by the notion "artificial intelligence"; what trends and solutions will make it possible to use it as efficiently as possible not only in the business processes of the companies, but also in all the spheres of modern society.

The Congress calls for the organization of the many sided, open scientific platform for the cooperation of the academic community and the real sector of the economy with the aim of obtaining the new knowledge, the exchange of information and the advanced experience, the examination of modern tendencies in the economy, the key factors and peculiarities of information's technological development in a society on conditions of globalization.

In order for all the participants to understand the essence of the events, the branding of the locations and all the materials of the Congress was realized (fig.1) through the brand positioning at different stages, taking into account all the possible communications with the audience.

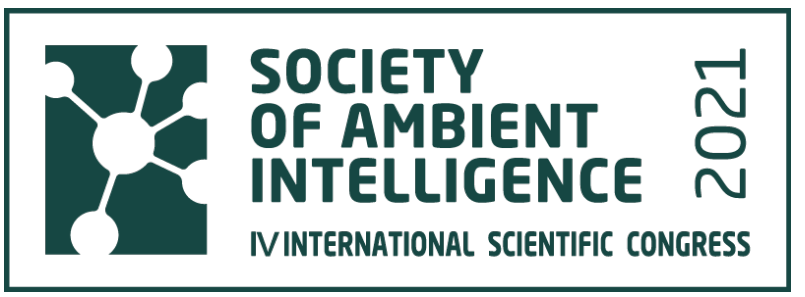

Fig. 1. Logotype ISC-SAI 2021.

The urgency of the information contents of the Congress is one of the main factors of its successful promotion. Many of the web resources, living on the Internet areas, do not meet the expectations of their

\footnotetext{
* Corresponding author: gushko77@gmail.com
} 
owners, - the fact, happening quite often and being a very unpleasant circumstance - they do not return the funds that were invested into the creation and the SEO promotion of the product.

The Congress website is an online brochure of the scheduled event with widened functionality for the registration and promotion. Since there is no time for the searching optimization in this sphere, the concept of the
Internet resource was realized: the page, aimed at the client's performance of the target action, consisting of ten structured blocks with the description of information. The resource provides the complete information of the events: a detailed description of the event and the format of its realization, the date and location, a list of speakers and the general information of them (fig.2).

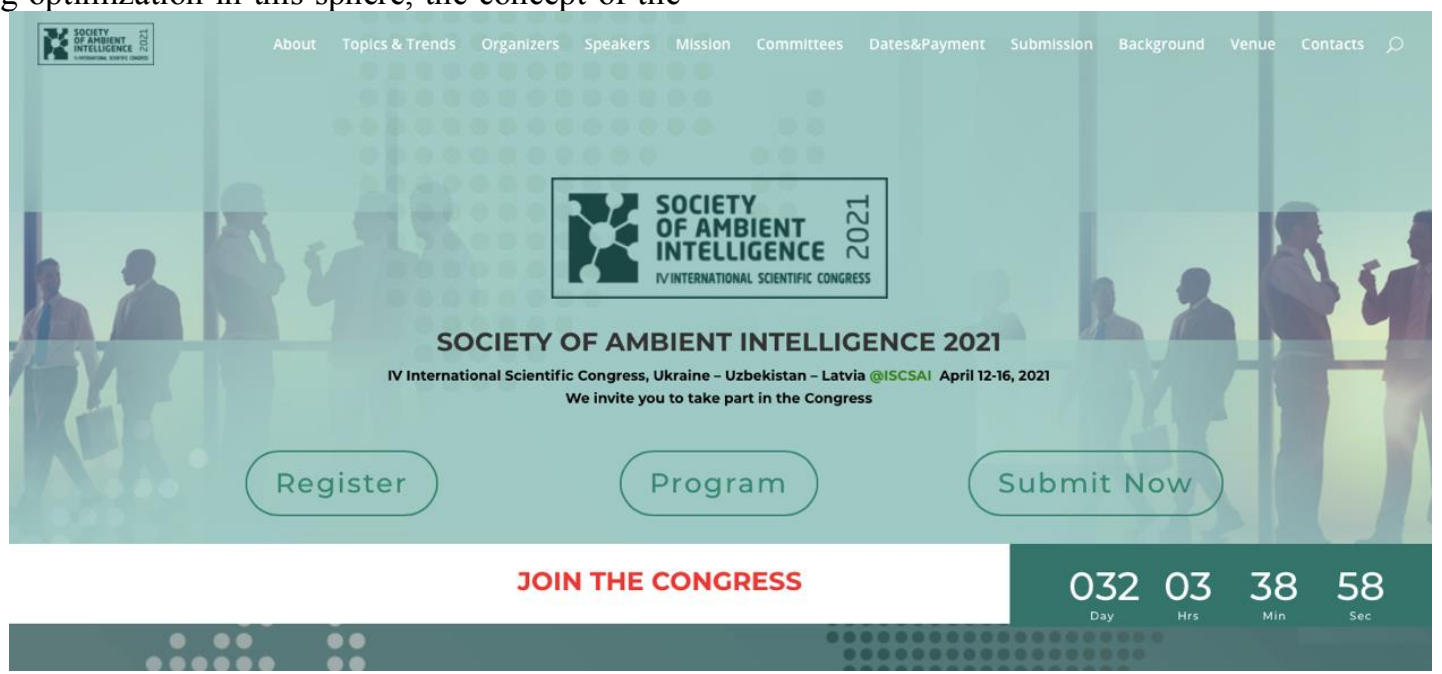

Fig. 2. Internet-Resource ISC-SAI 2021.

One of the most important factors in the success of business development is being in contact with the customer. The attraction of each new participant means the advertising budgets, and the longer the Congress can work with the already attracted participant, the higher will be the return of the investments. Thus, it is necessary to constantly work with the participants, by measuring their level of satisfaction.

The organizing committee used indices that allow us examine the change's dynamics in the relations of the participants with the brand within some time, to compare

\section{CUSTOMER SATISFACTION INDEX}

\begin{tabular}{|c|c|c|}
\hline 86 & $14 \%$ & $86 \%$ \\
\hline 86 & $14 \%$ & $86 \%$ \\
\hline 57 & 43 & $57 \%$ \\
\hline 57 & 43 & $57 \%$ \\
\hline 57 & $14 \%$ & $71 \%$ \\
\hline 86 & $14 \%$ & $86 \%$ \\
\hline 71 & $29 \%$ & $71 \%$ \\
\hline
\end{tabular}

the data obtained with the average indicators of the branch:

- NPS (Net Promoter Score) - the consumer loyalty index, reflecting the readiness to recommend the Congress to the other clients;

- CSI (Customer Satisfaction Index) - the index of participants' satisfaction.

The presented researches are aimed at the identification of the positive and negative sides of the event, as well as at the determination of the various criteria influence on the attitude of the participants towards the Congress (fig.3).

\section{parameters}

Relevance of section

Event program

Organization level

Practical sgnificance

Information content

Target audience

Research publication

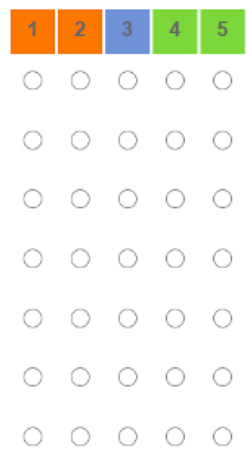

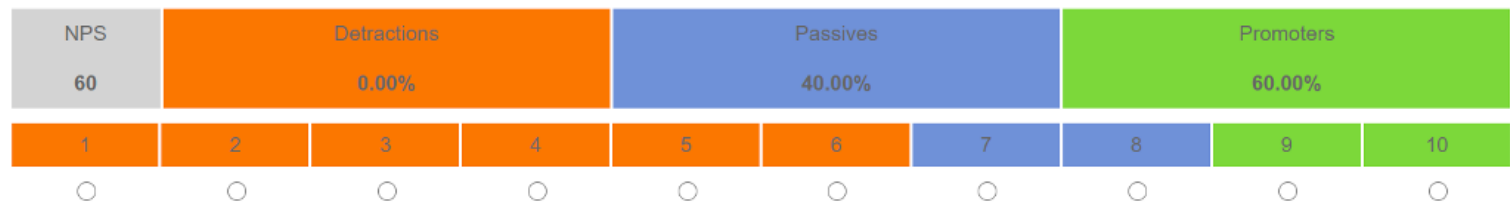

Fig. 2. Indices NPS/CSI ISC-SAI 2021.

To visualize and to analyze information about the Congress indicators, the processes and their efficiency, a dashboard of indicators was realized. The dashboards of indicators are the effective management tool that meets 
reasonably all the changing needs of the Congress

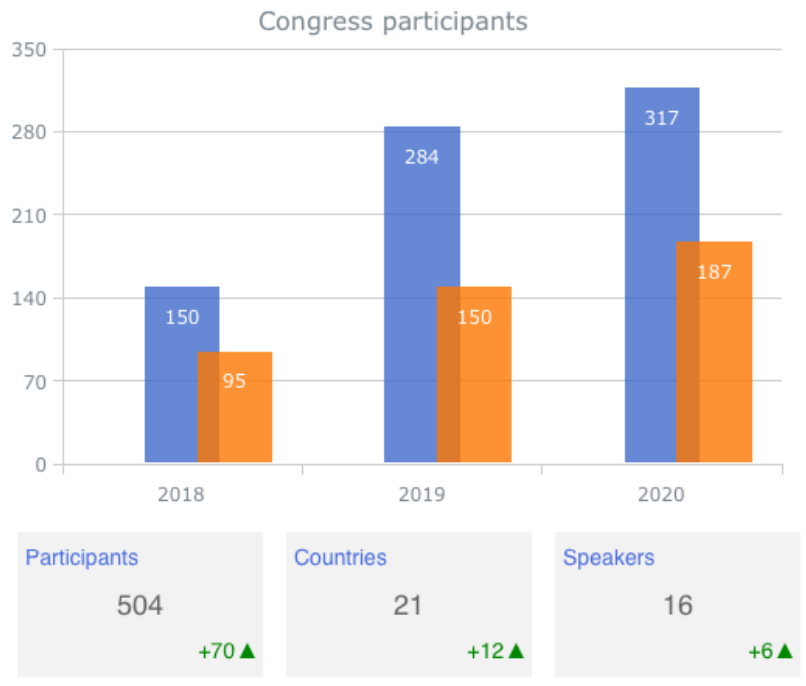

Organizing and Programming Committees (fig.3).

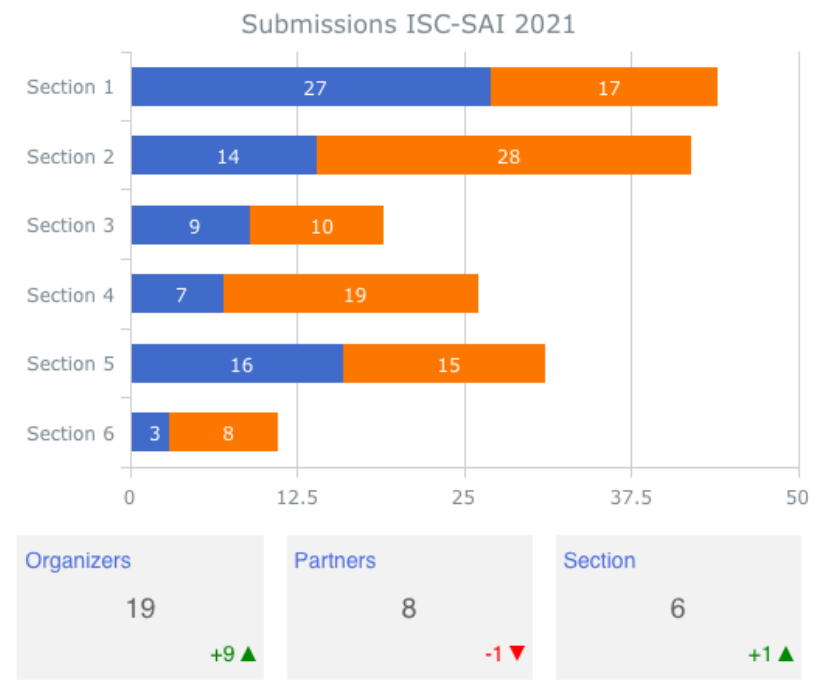

Fig. 3. Indicators Dashboard ISC-SAI 2021.

Conception of Congress:

- the work of the Congress is planned in the format of the panel discussions, according to the directions;

- the arrangement of the discussion panels according to the directions foresees the invitation of speakers from the academic and business spheres;

- the realization of the international student's competition of projects (the competition of cases' decision), according to the Congress directions. The competition will be held at two stages: the 1-st stage (national) - is the competition of the research projects/business-ideas; the 2-nd stage (international) is the decision competition of the cases, represented by the companies-partners of the Congress (the competition of projects);

- the organization of a platform of the legal clinics with the purpose of the experience exchange, the study of the best foreign and national practical trainings of the legal clinics, dealing with the different directions of the juridical education;

- the activity of the organizational and scientific committee is exercised via the procedure of the collective acceptance of organizational decisions with the division of responsibility levels of each of the organizers;

- the realization of the communications' format "business - universities - schools".

The Program Committee separated the following urgent directions for the discussion and approbation of research in the field of the Ambient Intelligence at the Congress:

- Information Technologies and Business Innovations;

- Business Communication and Linguistics;

- Digitalization of Society in National Legal Systems;

- Social Work and Artificial Intelligence;

- Ecology and Living Space;

- Mechanical Engineering and Mechatronic Systems

The investigations in these directions unite scientists, practical researchers and business representatives. This alliance foresees presenting of the solutions that may be adapted to the modern requirements, by offering the new models of distribution, the new behavior of the clients and the new business-models at that. The researchers offer the stable plans that will help to reduce the global rise in temperature, to eliminate the poverty and to protect the environment from the further destruction.

The information technologies play an important role in the creation of the new economic possibilities and business-innovations today. The aim of this direction is to study the role of the modern information technologies in the acceleration of the economic growth and the creation of the new economic possibilities, the development and the realization of the digital economic policy and the influence of the digital economy on the national and the international investments and the creation of cost.

The digital technologies develop intensively with the growing scope of information, the increase of the vast information tracks and data bases. They are widely used in all the spheres of social life, in the activity of the state and the social institutes, - the fact, characterizing the significant development of the modern society. And due to that, the law becomes not only the tool, which provides the digitalization of the economy and the other branches, but it changes its forms, contents, structure and mechanisms. Therefore, the new digital reality presents the new demands to the science of law and to the legal practice. It allows develop the efficient tools and models of legal regulation. And the juridical investigations in this direction offer the new legal solutions for the practical researchers.

Due to the tools of the information technologies, the style of communication in the modern world has suffered the radical changes, by giving the place to the revolutionary method of communication, which ignores the traditional barriers. The new approaches to the research of the theoretical and the applied problems of the intercultural communication, the transportation of the pedagogical strategies of language training in education, 
the modern forms of education integration are offered today.

The artificial intellect has already become the integral part of all the spheres of life, which offers the unique methods of data processing to the modern world. And the social sphere has the new qualitative and organizational transformation today, due to the use of the information technologies. The investigations in this direction foresee the use of the artificial intellect in the social sphere and the prognostication of demand on social services.

It's important to understand that the transformation of the society and its "digitalization" helps, first of all, to promote the tools for the solution of different urgent tasks: the increase of labor productivity, the reduction of the part of the monotonous or dangerous procedures for people and, at last, for the widening of human possibilities.

The digital transformation happens slowly, unequally, it's faced with the great number of the barriers - both technological, political and the social ones. The formation of the digital society is gradually freed of the hard labor and the new professions are created, but the realization of the modern tools are spread at the very different levels and they may cause the unexpected social effects already today.

Thus, the introduction of the environmental intellect into life in all sections of the society, including the educational one too, doesn't only push a person to the life side of the road so far, but it makes him (her) to develop in the new directions.

The realization of the platform in the ISC-SAI 2021 format by the University community with the combination with the real sector of the economy will promote for the unification of the professionals and the researchers of the different districts, who discuss the modern calls of the digital society in the thematic tracks.

The Congress participants are offered to present both the theoretical and practical results and to take part in the discussion panels on the urgent problems of the present time too. The presentations of the practical works of the professionals from the different countries, the discussion of challenges, concerning the introduction and development, and the exchange of the conclusions and the corresponding results are foreseen.

\section{References}

1. This concept was firstly used by Mark Weiser of IBM. See Mark Weiser, 'The computer for the 21st century' (1991) 265 Scientific American 94.

2. N. Dijk, 'Property, Privacy and Personhood in the World of Ambient Intelligence' (2010) 12 Ethics and Information Technology 57, (n 13), p61.

3. Mary Rundle and others, At a Crossroads: 'Personhood' and Digital Identity in the Information Society (STI Working Paper 2007/7, 2008)

4. Mireille Hildebrandt and Bert-Jaap Koops, 'The Challenges of Ambient Law and Legal Protection in the Profiling Era' (2010) 73 Modern Law Review 428 